practical instruction in ophthalmology of not less than ten weeks' duration, and that no student should be admitted to the final examination unless he presents a certificate to the effect that. he has attended such a course regularly, and that his work in connection therewith has reached a satisfactory standard."

Great Britain, therefore, still lags behind the Irish and large majority of American and other foreigh universities in the teaching of ophthalmology to undergraduates, for at them it forms one of the subjects of the qualifying examinations and the examiners are invariably ophthalmic surgeons. Experience has shown that without such regularly applied tests by licensing bodies there can be no guarantee that a uniform standard of knowledge of ophthalmology has been acquired by students coming from different schools. The General Medical Council would not dream of accepting a certificate from a student's teacher that he had attended instruction regularly, and that his work had reached a satisfactory standard, as evidence that he had sufficient knowledge of medicine, surgery or midwifery to entitle him to a diploma to practise. Why then, if a knowledge of ophthalmology is admitted to be essential, should a different method be adopted for testing it to that which is employed in other subjects?

\title{
Graduate Teaching
}

The report on the graduate teaching of ophthalmology in the Transactions of the American Ophthalmological Society is signed by Drs. E. Jackson, F. H. Verhoeff and T. B. Holloway. Some of the passages in it are so much in accordance with the experience of those who have devoted special attention to the subject in this country that it is well to quote them at length.

Thus dealing with the lack of adequate preparation of many of those who take up ophthalmology as a special branch of practice the report says :

"The average undergraduate student has been expected to learn a great deal about the fundamental branches, anatomy, physiology, and pathology, that did not seem to have any practical connection with his subsequent studies in practice. And, having spent his time acquiring so much that seemed useless, he has assumed that he has been taught all that could be useful. The young doctor of medicine, advised not to think of a speciality until long after he has put the study of anatomy behind him-he hopes for ever-assumes that he was taught, along with the relations of the structures in Scarpa's triangle, all the anatomy of the eye that he will ever need to know.

"He believes that, having been puzzled by the layers of the retina, when he had no interest in the purposes they serve, he learned as much of the histology as he can ever find useful. He was not conscious of any significance that might attach to the behaviour of visual purple, and the suggestions that might come from it as to the influence of 
exhaustion or after-images on visual acuity. The facts of pathology were presented in relation to the appendix, the spinal column, the liver, or the kidney; but were not understood or appreciated with regard to intraocular pressure, transparency of the media, or sclerosis of the retinal vessels. In a word, the man or woman who has been dubbed a doctor in medicine, turns to ophthalmic practice as a special field of work with the impression that he has all the training he needs as to the fundamentals of medicine, and only lacks an acquaintance with clinical methods and appearances and a perfected operative technic to fit him for the duties of a practising ophthalmologist.

"The first thing an aspirant must be taught is that there is a good deal of the anatomy, histology, and embryology of the eye that he has never learned in the medical college and must know before he can make a good clinical examination of an eye; that physiologic optics is a large subject, fundamental to ophthalmic practice, and directly entering into the most extensive branch of the work of the oculist; and that pathology appears in a new aspect in relation to the eye, and gives significance to what is seen with the ophthalmoscope or ocular microscope.

"It should be made clear to everyone interested that the first step in preparation for special practice is to study the special anatomy, histology, embryology, and physiology of the eye; elementary optics with so much trigonometry as is needed for its understanding ; pathology as manifested in the ocular tissues; and bacteriology of the ocular infections, both superficial and deep.",

The oldest school of ophthalmology in the English-speaking world is that connected with the Moorfields Eye Hospital; it was established in 1810 by Dr. R. J. Farre and Benjamin Travers, when the institution was known as the London Ophthalmic Infirmary. The aims of the school in its early days were well set out by William Lawrence (afterwards Sir William), who joined it in 1814 , and it is interesting to compare them with those above quoted as the requirements of to-day. In the introduction to his "Treatise on Diseases of the Eye," published in 1833, he says: "The course of proceeding in learning the diseases of the eye must be the same as that for diseases in general. The art of treating diseases, or medicine, taken in its most extensive sense, is founded on the sciences of anatomy, physiology, pathology, and therapeutics ; in other words, a knowledge of the healthy structure and function must be first obtained; and, lastly, the external agencies capable of influencing the body, so as to remove disease or restore health, must be studied."

How well he put into practice the above views may be gathered from perusal of his treatise, which was based on the lectures which he delivered at the Iondon Ophthalmic Infirmary on anatomy, physiology, and diseases of the eye.

As the staff of the hospital increased in numbers, and the knowledge of ophthalmology and its ancillary subjects enlarged in amount, so we find the teaching. of its different branches became 
divided up into separate courses. Dalrymple, who was appointed on the staff in 1832, delivered soon after a course of lectures upon the anatomy of the human eye, accompanied, as he says "by a series of dissections laboriously and minutely followed out"; these were published in book form in 1834 .

The classical lectures of Sir William Bowman "on the anatomy of parts concerned in the operations on the eye," were first delivered at the Moorfields Hospital in 1847.

Regular systematic courses of instruction in the use of the ophthalmoscope were established by Marcus Gunn in 1883, and ever since have formed a most attractive feature of the postgraduate teaching at Moorfields.

*Hulke has described how in his early days errors of refraction were so little understood that a small tortoise-shell case, containing half a dozen convex and concave spherical lenses, which could be easily carried in the trousers pocket, was held to comprise a sufficient stock for every trial, and that it was not until the publication of Donders' classical work on disorders of refraction and accommodation that much progress was made in their scientific diagnosis and treatment.

Soelberg Wells and then John Couper were the first chief exponents of the correction of refractive errors at Moorfields, but it was not until William Lang was appointed on the staff in 1884 that systematic courses of instruction in elementary optics and the refraction of the eye were established.

The teaching of pathology, which as already stated was started by Lawrence, was greatly aided by the establishment of a pathological laboratory and museum about 1855 . Here the curators have, in succession, ever since conducted practical courses of instruction.

In 1907 a bacteriological laboratory was instituted with a separate presiding officer, and practical instruction in this branch of ophthalmology became added to the curriculum.

Though operative dexterity is usually an innate gift much can be acquired. The methods of procedure and the art of handling instruments can be taught on animals' eyes fixed in a suitable frame. For several years, during the latter part of last century and the beginning of this, Stanford Morton conducted private courses of instruction of this sort which were most deservedly popular, and which later became incorporated with the regular teaching conducted at Moorfields.

A considerable stimulus to the study of the preliminary essentials of a sound ophthalmic training has been given of late years by the conferring of diplomas in ophthalmology, in the first instance by the University of Oxford, and more recently by the

\footnotetext{
*Trans. Ophthal. Soc., Vol. VII, p. 20, 1887.
} 
Royal Colleges of Surgeons and Physicians in London. To obtain these diplomas, candidates before presenting themselves for examination, have to attend certain prescribed courses of instruction on anatomy and physiology of the eye, physiological optics and pathology. The result has been the establishment at the University of Oxford, and at the different Ophthalmic Hospitals in London of special courses to meet these requirements.

This brief outline of the growth of ophthalmic teaching in this country will serve to show that it has developed, not as the result of any set plan, but by gradual accretions to meet the requirements of students and the advances of knowledge.

The committee of the American Ophthalmological Society in the concluding passages in its report states :

"It is certainly surprising that no one has ever offered to donate a large sum for the advancement of ophthalmology. This must be due to the fact that our needs have not been sufficiently advertised."

It is probably still more surprising that the teaching at Moorfields has been so successfully carried on for over one hundred years without any endowment, the only funds available being those derived from the students' fees. How much this redounds to the self-sacrificing services of the members of the surgical staff, past and present, may be gathered from the next paragraph of the report which runs as follows :

"The chief difficulty in organizing a graduate school of ophthalmology is in obtaining properly qualified teachers who are willing to devote sufficient time to the school. Most ophthalmologists feel that after they have given a large part of their time to clinical work in the hospital they must devote the rest of their time to making a living in private practice. The only way this difficulty can be overcome is to provide adequate salaries for the teachers."

\section{ABSTRACTS}

\section{I.-DISEASES OF RETINA}

(I) Sourdille, G. (Nantes).-A method of treating detachment of the retina. (Une méthode de traitement de décollement de la rétine.) Arch. d'Ophtal., July, 1923.

(1) In this paper, presented to l'Académie de Médecine, Prof. Sourdille recounts his experiences, and describes the technique he employs in the treatment of detachment of the retina by operative measures. He is much more sanguine than most writers on this subject and certainly his published results seem to justify his optimism. He deplores the fact that repeated failures have so 